\title{
“Do outside": corpo e natureza, medo e gênero no surfe universitário paulistano
}

CDD. 20.ed. 398.36
616.89
797.15

\section{Resumo}

Ao objetivo primeiro desta pesquisa, descrever as dinâmicas do surfe e os significados de sua prática, em especial a relação ser humano/natureza estabelecida por meio do esporte, somaram-se outros objetivos: problematizar a aproximação do pesquisador de seu campo de investigação, a possibilidade de um pesquisador realizar uma investigação através de seu próprio corpo e discutir a questão de gênero no surfe. Sobre o objetivo primeiro desta pesquisa, vivendo e descrevendo as dinâmicas do surfe encontrou-se os significados da relação do surfista com o mar nas sensações corporais experimentadas nas técnicas do remar, sentar, dar o joelhinho e dropar a onda. Que ser capaz de passar a rebentação é associado a um retorno bem sucedido à comunhão do homem com a natureza, sendo as cores, formas e sensações do "outside" o privilégio daquele que vence as dificuldades do tornar-se e ser surfista. Mas, que estas sensações são tidas como possibilidades de corpos corajosos e hábeis, "a priori", entendidos como corpos masculinos. 0 surfe como campo em que o feminino é visto ainda como exceção dá a pensar que os esportes na natureza e a educação ao ar livre, embora tenham potencial de promover novas condutas políticas e a virtuosa sensibilidade ambiental, não estão livres de reproduzir outros padrões de dominação.

UnIteRMos: Surfe; Natureza; Corpo; Risco; Gênero.

\section{Introdução $^{1}$}

When a sociologically circumscribed group has no other aim in life but to live in a world of waves or snow, when an entire life is devoted to one moment of ecstasy, it is time to consider the most intimate ways by wich human beings build their own cultural landmarks and make them meaningful (Midol, 1993, p.27).

Ao objetivo primeiro desta pesquisa, descrever as dinâmicas do surfe e os significados de sua prática, em especial a relação ser humano/ natureza $^{2}$ estabelecida por meio do esporte, somaram-se outros objetivos percebidos relevantes e elaborados ao longo e após a coleta dos dados: problematizar a aproximação do pesquisador de seu campo de investigação e discutir a questão de gênero no surfe.

Este artigo trata, portanto, de uma fase inicial de pesquisa, em que se optou por dispor de relatos em primeira pessoa. Entretanto, procura retratar uma experiência científica e lidar com problemas concernentes à interface da Educação Física com as Ciências Humanas, que só poderiam emergir, em sua versão proposta pelo surfe, deste empreendimento pessoal que foi a pesquisa através da convivência com os sujeitos de sua prática e da experimentação dos movimentos e saberes ${ }^{3}$ do surfe.

Essa pesquisa foi aprovada pelo Comitê de Ética em Pesquisa da Escola de Educação Física e Esporte da Universidade de São Paulo e contou com o apoio do Conselho Nacional de Desenvolvimento Científico e Tecnológico (CNPq) para sua realização. Todos os sujeitos participantes assinaram um termo de consentimento para utilização e divulgação dos dados apresentados a seguir. 


\section{Metodologia}

O método utilizado neste estudo foi a etnografia. Com o intuito de descrever as dinâmicas do surfe e de seus praticantes, os dados foram coletados através de observação participante e registrados em diário de campo.

Para esta fase inicial foi selecionada, nos moldes sugeridos por SPRADLEY (1980), a situação social a ser analisada entre três arestas de um triângulo: determinou-se a atividade: o surfar; o cenário/local de prática: a praia e seus atores: os surfistas.

Sobre o perfil dos surfistas brasileiros, em 1997, Vasconcelos, Ramos, Steinman, Botelho e Nahas identificaram por meio dos 920 questionários que retornaram após serem distribuídos por todo o Brasil em revista especializada, que $95 \%$ eram homens, $55 \%$ tinham entre 15 e 24 anos, $27 \%$ residiam na região sudeste e $26,9 \%$ na região sul, $56,6 \%$ tinham mais de cinco anos de prática, $69,1 \%$ se consideravam surfistas recreacionais, $28,1 \%$ amadores e 2,8\% profissionais, $78,3 \%$ utilizavam prancha pequena ("short board" ou pranchinha) e que a média de frequência de prática desta amostra era de duas a três vezes por semana de duas a três horas por sessão.

Tendo isto em consideração, os sujeitos deste estudo corresponderam a cinco surfistas recreacionais de pranchinha, universitários que eventualmente participavam de campeonatos amadores, residentes em São Paulo, com idades entre 23 e 27 anos, com sete a 20 anos de prática de surfe e que frequentavam a praia em média uma vez por semana. Os critérios de seleção dos surfistas a serem acompanhados nesta pesquisa foram: o tempo de experiência na modalidade, a frequência de prática e o reconhecimento do indivíduo como surfista por outros surfistas.

Isto porque, embora os próprios surfistas descrevessem a atividade como individual, o surfe como a relação de si com o mar, percebi que para a realização desse estudo a condiçâao "sine qua non" foi que pudesse compartilhar dos momentos de prática e atividades paralelas de um grupo. Ou seja, que tivesse acesso a rotinas do esporte, que não limitadas a uma impressão pessoal, mas vinculadas a um coletivo, de forma que os sentidos da prática fossem compartilhados e as divergências viessem à tona, jogando luz às diferentes faces de uma mesma realidade.

Este grupo, em específico, foi selecionado por se apresentar acessível à pesquisadora, visto que as "surftrips" eram planejadas e sempre saíam da Universidade na qual cursava graduação, e utilizar linguagem e praticar atividades comuns às dinâmicas de outros grupos e indivíduos conhecidos em pesquisa piloto, sugerindo sua representatividade. Embora nas observações os cinco surfistas nem sempre estivessem juntos.

O acompanhamento do grupo se caracterizou, então, por situações em que ao menos um desses cinco surfistas estivesse presente. Ou seja, durante o acompanhamento do grupo notou-se sua constituição mutável e sempre ampliada. Outros surfistas conhecidos, tidos como "brothers", ou os irmão, de um ou mais adeptos do grupo, suas namoradas, familiares e pessoas a serem introduzidas na prática poderiam estar presentes e também forneceram dados à análise.

Embora contando com atividades também fora dela, o campo primeiro desse estudo não poderia deixar de ser a praia, que é aqui entendida em seu sentido mais amplo. Já que, no caso deste grupo de surfistas, que residiam na cidade de São Paulo, a localidade específica da sessão de prática dependia da acomodação, orçamento e tempo disponíveis, ou das condiçôes do mar e dos ventos, e era determinada pelo próprio grupo, muitas vezes, apenas depois de serem verificadas as condições de diferentes praias.

A coleta de dados foi realizada, então, em diferentes localidades do Estado de São Paulo, em sua maioria no litoral norte, nos municípios de Bertioga e São Sebastião ${ }^{6}$, tais como: Boracéia, Juquehy, Praia da Baleia, Camburi, Maresias, Paúba, e, no litoral sul, município de Guarujáp: Praia das Pitangueiras e Praia do Tombo. Nestas praias também se deu a iniciação da pesquisadora ao surfe.

Isto porque, entendeu-se durante o trajeto investigativo que a experiência corporal da própria pesquisadora seria importante para a apreensão dos significados da prática do surfe. Inspirado na experimentação científica de Corpo e alma: notas etnográficas de um aprendiz de boxe (WACQUANT, 2002) e procurando acessar aquilo que não pôde ser visto da areia, este estudo buscou retraçar uma "experiência pessoal de iniciação a um ofício do corpo". E pretendeu afirmar a necessidade de um esforço maior por parte das abordagens humanas em pesquisa em capturar e restituir o que o autor chama de "a dimensão carnal da existência".

A observação participante foi realizada de outubro de 2004 à maio de 2005, em tantas atividades quantas foi possível acompanhar, de natureza e duração variáveis, tais como: viagens de um dia, viagens de um fim de semana, festas, conversas, assistir a filmes de surfe , andar de "skate", aulas de surfe na piscina (oferecidas pelos praticantes 
a iniciantes), entre outras. Isto caracterizou pelo menos um encontro semanal com os sujeitos da pesquisa, realizado por um período de sete meses.
E o contato entre a pesquisadora e os surfistas se manteve nos anos subsequentes, trazendo "a posteriori” elementos para a análise.

\section{Resultados e discussão}

\section{Corpo, alma e onda: prática, medo e autoetnografia}

What binds these windsurfing communities is a shared understanding of the pleasure of windsurfing: the buzz gained from blasting along the water for the first time, or progressing to sail at 30 miles an hour, or jumping 10 feet into the air. Windsurfing participants were not concerned with their health, longevity, and selfpreservation, but denoted a relationship between body and self that emphasized intense but shorterm and the self-actualized "inner" or "felt" (no "displayed") body (WHEATON, 2000, p.268).

A iniciação da autora no surfe foi a estratégia que pareceu mais adequada em um momento de pesquisa no qual apreender os aspectos sociais que se esperava descrever e analisar tornava-se cada vez mais difícil para alguém que não pega onda ${ }^{9}$.

A passagem por todas as fases do que chamamos provisoriamente de "percurso surfístico", ou seja, a aprendizagem do surfe ou o processo de tornar-se surfista, culminando com a capacidade adquirida de passar a rebentação ${ }^{10}$ sem ajuda e da execução do "drop", descida em pé sobre a prancha pela face da onda, apresentou-se imprescindível para continuar descrevendo e problematizando a prática do surfe. Assim como em WACQUANT (2002):

[...] a necessidade de compreender e dominar plenamente uma experiência transformadora que eu nem desejara nem previra, e que por muito tempo permaneceu obscura para mim, que me levou a tematizar a necessidade de uma sociologia não somente do corpo, no sentido de objeto, mas também a partir do próprio corpo como instrumento de investigação e vetor de conhecimento (p.12).

No caso desta pesquisa, esta decisão foi tomada após a identificação da presença no "outside 11 " como indispensável para acessar os diálogos e atuações dos pesquisados e único meio, considerado por eles, legítimo de convivência com a modalidade ${ }^{12}$. Esta iniciativa permitiu estruturar relações de respeito e confiança mútuos que possibilitaram retomar os dados anteriormente coletados e realizar sua aferição.
Assim, entendendo, como DAólIO (2001), que adotar o referencial antropológico de pesquisa significa de alguma forma colocar-se no lugar do outro procurando compreender sua dinâmica cultural própria, emprestei meu próprio corpo à investigação científica, me colocando no lugar do surfista: o "outside".

Apenas durante o treinamento do surfe foi estabelecida uma relação de identificação com os praticantes para acessar certos códigos de conduta interditados aos espectadores. É pertinente lembrar, entretanto, que quando se toma esta decisão, consequentemente limitase o uso do caderno de campo e gravador, visto que não é possível atravessar a rebentação e permanecer na água e preservar o equipamento intacto. E, mesmo que se pudesse fazê-lo, dividir-se-ia a atenção entre documentar o observado e sobreviver à situação peculiar que é para um iniciante estar no "outside". Por isso, não disponho nesta sessão de falas literais de surfistas, que poderiam ser usadas para ilustrar os argumentos desenvolvidos, mas sim de percepçóes ainda mais pessoais da pesquisadora sobre o que se passa no corpo do surfista. Dados internalizados, literalmente incorporados durante o processo de aprendizagem técnica ${ }^{13}$. Isto vai ao encontro do que sugere BOURDIEU (1990):

Os problemas colocados pelo ensino de uma prática corporal me parecem encerrar um conjunto de questôes teóricas de importância capital, na medida em que as ciências sociais se esforçam para fazer a teoria de condutas, que se produzem, em sua grande maioria, aquém da consciência, que se aprendem, pode-se dizer, por uma comunicação silenciosa, prática, corpo a corpo [...] Há um modo de compreensão totalmente particular, em geral esquecido nas teorias da inteligência, e que consiste em compreender com o corpo. Há uma infinidade de coisas que compreendemos somente com o nosso corpo, aquém da consciência, sem ter palavras para exprimí-lo (p.218-9).

Para este relato, então, precisei estar disposta tanto à aprendizagem corporal do surfe, quanto ao esforço consciente de descrever as suas fases, transformá-las em palavras, realizar seu registro para o debate científico. Este procedimento procurou atender à questão posta por WACQUANT (2002): 
[...] como dar conta, antropologicamente, de uma prática tão intensamente corporal, de uma cultura totalmente cinética, de um universo no qual o mais essencial transmite-se, adquire-se e desdobra-se aquém da linguagem e da consciência - enfim, de uma instituição feita de homem (ns) e que se situa no limite prático e teórico da prática? (p.15).

Claro que há um trânsito dos sentidos do surfe na praia e dos esportes na natureza em geral na esfera social mais ampla, mas é inegável que somente depois da rebentação acontecem as ações mais fundamentais do surfe. Isto sinaliza, tal como WACQUANT (2002), para a importância da consideração não só teórica, mas metodológica da pessoa estudada e do pesquisador como possuidores de um corpo, mas que também o são (um corpo).

Aperfeiçoar a condição física, adquirir os gestos, sentir a dor da ação, o gosto salgado do afogamento, as torções do caldo $^{14}$, a aspereza da areia, incorporar as representações de oceano, saber ler a onda, entender os ventos, usar da tática, passar a rebentação, aprender na prática a lógica do surfe tornou-se essencial para fixar o fenômeno investigado em texto.

Num primeiro momento, pensei que seria importante observar os surfistas no "outside" para ouvir o que diziam uns aos outros e como se dava a interação entre eles (principalmente no caso da regra de prioridade pela onda e do localismo ${ }^{15}$ abordados em outro artigo). Mas, o processo de aprendizado e de aquisição de autonomia para alcançar o "outside" trouxe, ele mesmo, elementos centrais para esta análise.

Lembrando que como todo recorte de pesquisa, este trabalho apresenta limitações peculiares, posso dizer que a principal delas foi a questão de gênero. Visto que acompanhei um grupo composto apenas por surfistas homens, notei que especialmente às mulheres espectadoras era dificultada a apreensão de certas narrativas posteriores às sessóes de surfe. Isto se dava, em parte, por que elas não demonstravam interesse pelos detalhes, visto que não eram praticantes, em parte, porque a disposição ao esforço físico e a coragem demandadas para iniciar-se nesta atividade eram usualmente atribuídas, pelos surfistas acompanhados, ao universo masculino. Parecia não ser comum falar muito sobre surfe com mulheres em geral, apenas com aquelas que também surfavam, e surfavam bem.

Portanto, minha feminilidade foi percebida como condição de produção desta pesquisa. E minha iniciação no surfe tornou-se imprescindível por dois motivos: 1) Entre os surfistas, parecia haver uma ideia de que se eu não o fizesse, se não corresse o risco, se não sofresse as escoriações da parafina ou se não experimentasse as secreções de adrenalina quando no "lip ${ }^{16 "}$ da onda, eu não poderia nem admirar, nem compreender a prática do surfe. Muito menos escrever sobre ela. É válido lembrar que além da mídia especializada, os empreendimentos investigativos e a confecção de livros sobre o surfe no Brasil, desde seu princípio, foram iniciativas quase que exclusivas dos próprios surfistas. Talvez por isso foi preciso um conhecimento de causa, um saber corporal, para receber certo tratamento por parte deles, que possibilitasse a teorização e problematização do surfe, o que converge com a pergunta metodológica de Bourdieu (1990) e WACQuAnt (2002); e 2) Sendo mulher, tentei transpor a barreira do gênero no compartilhar da ação, no exercício social da atividade. Surfando ao lado dos sujeitos conquistei, mais pelo esforço do que por habilidade, o acesso às questóes da modalidade e aos significados do surfe compartilhados entre eles e agora, entre nós. Isto quer dizer que os surfistas passaram a consentir minha presença, trocar impressões comigo e a me explicar situações, antes inacessíveis, apenas depois de me perceberem no "outside".

Estas circunstâncias não são incomuns na análise social sobre o esporte. WHEATON (2000) também relata que sua pesquisa entre praticantes de "windsurf" homens só se tornou possível por sua condição, no caso prévia, de praticante: "Consequently, as a female researcher studying a very male-dominated subculture, my role as an active and competent windsurfer was vital in gaining access" (WHEATON, 2000, p.261).

Isto posto, comecei com simulações em pranchas desenhadas na areia para treinar o impulso com os braços que é seguido do "drop", remadas ${ }^{17}$ na espuma ${ }^{18}$ do raso - como se faz com as crianças para sentir a marola ${ }^{19}$ carregando a prancha, alguns treinos de natação para garantir o condicionamento físico e outros poucos de apnéia ${ }^{20}$ para suportar os caldos, tudo isso contando com a presença de um dos pesquisados, que assumiu imediatamente o papel de instrutor à minha disposição de aprendiz.

Depois, nos dias calmos, arrisquei chegar ao "outside" com ajuda - puxadas e empurrões, rebocadas, gritos de incentivo e acompanhamento e instruções para as situações inesperadas. Então, passei a acompanhar o grupo em qualquer situação de mar. Mesmo que fosse fracassada a tentativa de passar a rebentação, eu voltava para a areia com a experiência internalizada daquele tamanho de onda, daquele tipo de correnteza, daquela temperatura da água. Mesmo que o joelhinho ${ }^{21}$ fosse ineficiente e a remada insuficiente insistia até a exaustão. 
E esta situação de pesquisa também convergiu com os achados de WHEATON (2000) entre os windsurfistas: "In addition to skill and attitude, commitment to the activity was central to attaining subcultural status. Those individuals who tried hard and improved, irrespective of their proficiency level, gained respect" (p.260).

Diz-se que é preciso saber dar um joelhinho ${ }^{22}$ para passar a rebentação. Mas, apenas foi possível compreender a importância do joelhinho, não só como algo que o surfista faz e sobre o que fala, mas como o resultado técnico de um deslocamento que possibilita escapar da queda violenta da massa de água diretamente contra nosso corpo, após experimentá-lo.

Para compreender que o joelhinho é uma forma de evitar o dolorido choque com o "lip" da onda ou a instabilidade da espuma agitada que faz o surfista desprender mais energia que o necessário para se manter na prancha, e que dificulta muito avançar na remada, é preciso sentir estas ameaças.

Quando se aprende a mergulhar com a prancha por debaixo do turbilhão da onda em fusão com o fundo, seguida da liberação do mesmo, propiciada pela flutuação do equipamento é que se percebe o quanto este movimento é imprescindível ao surfar, e, especificamente, ao surfe de pranchinha. Ao notar a onda, avaliá-la em segundos, tomar ar, afundar o bico, inclinar a prancha, mergulhar, empurrar sua rabeta $^{23}$ com o joelho e emergir do outro lado para inspirar novamente e repetir esta sequência de atos, tantas vezes quantas forem as ondas que chegam a praia enquanto se tenta alcançar o "outside", demonstra-se a determinação, a persistência, o controle e a habilidade que são lidos como sincronia com o mar e aceitação da presença do surfista pelo oceano.

Quando se é capaz de minimizar o medo e o receio de sentir a rebentação e controlar as ações que devem se seguir às ameaças percebidas é que se sente o quão fluida pode ser a entrada do surfista no oceano. Juntamente com a excelência do "drop", a excelência do joelhinho caracteriza os homens do mar no surfe. Isto converge com o que Mauss (2003) chamou de educação do sangue frio, exemplificada no montanhismo:

Creio que a educação fundamental das técnicas que vimos consiste em fazer adaptar o corpo a seu uso. Por exemplo, as grandes provas de estoicismo etc., que constituem a iniciação na maior parte da humanidade têm por finalidade ensinar o sanguefrio, a resistência, a seriedade, a presença de espírito, a dignidade, etc. A principal utilidade que vejo em meu alpinismo de outrora foi essa educação do meu sangue frio, que me permitia dormir em pé num degrau à beira do abismo (p.421).
Saber furar a parede da onda sem ser arrastado por ela, ou seja, deslizar harmoniosamente sob a massa de água em rotação e ser impulsionado para adiante pelo empuxo permite sentir-se à vontade com a ondulação incessante. Assim pode-se submergir e emergir, tranquilamente entre remadas até o ponto em que se pode descansar, onde as ondas não rebentam e a água não mais nos atinge agressivamente, o "outside".

Outra das técnicas do "outside" que é esclarecedora é o sentar na prancha. O equilíbrio que permite balançarmos suavemente sentados, com a prancha pressionada entre os joelhos, a admirar o horizonte e avaliar a formação das ondas que chegam. Esta técnica, o aparentemente simples sentar na prancha, é necessária para termos um retrato da praia e do cenário natural, simbolicamente reservado àqueles que são bem sucedidos nesta empreitada corporal de "retorno" à natureza que é o alcance do "outside".

O privilégio dos reflexos do sol e da lua no mar, das cores vistas de um outro ângulo, pequenos arcoíris formados no quebrar do "lip" da onda quando o mesmo é espalhado pelo vento terral ${ }^{2}$, de um outro lugar, do "outside", que é o lugar do surfista, dão acesso a novos formatos para as ondas vistas de lado e por trás ${ }^{25}$ e são o que se adquire de especial para além da capacidade de dropar a onda quando se é surfista. O sentar é não só uma técnica de espera e descanso, mas também de contemplação que só pode acontecer com o domínio do fino equilíbrio exigido pela prancha para permanecer estável ${ }^{26}$.

Quando sentado, o surfista repara no horizonte as massas de água aproximando-se e deve saber reconhecê-las. Se quebrarem com impulso suficiente para o levarem com elas são surfáveis. Neste caso, se a parede de água abre para a esquerda, são esquerdas; se abre para a direita, são direitas. E há as que quebram para os dois lados comportando dois surfistas, um na direita e um na esquerda. Já, se quebrarem com impulso excessivo ao longo de toda sua extensão e de uma vez são insurfáveis, "fecham" ou são fechadeiras. E, se não quebram, são marolas. Se forem lentas e largas, de "drop" fácil, oferecendo pouco impulso são gordas e se são rápidas, desafiantes e tubulares são cavadas ou ocas.

Quando avistam a série ${ }^{27}$ entrando, os surfistas se movimentam no "outside" em busca do melhor posicionamento para pegar a onda. Inicialmente remam em sua direção e na direção de onde primeiro começa a quebrar para, depois, sentando rapidamente e virando a prancha com precisão, prepararem-se para remar em direção à praia. Devidamente posicionados no pico $^{28} \mathrm{da}$ onda atingem, com o movimento alternado dos braços, velocidade aproximada a sua para 
que ela os incorpore. Assim, percebem-se carregados na crista por um instante, no alto do mar, como se estivessem apoiados de bruços em uma parede de água em deslocamento e, em um movimento único e confiante, devem se posicionar de pé e deslizar sobre a parede da onda para baixo e para o lado, sem imbicar $^{29}$, despencar de cabeça ou rolar.

Este movimento para mim demorou muito para se transformar de caldo, vaca ${ }^{30}$ ou caixote ${ }^{31}$ em "drop". O quase afogamento me levava a pensar em desistir, mas os surfistas - como eu, um dia iniciantes - diziam que "é assim mesmo". Testemunhavam a favor da insistência, incentivando-me a repetir a amarga experiência. Asseguravam-me de que um dia seria tal o conhecimento do mar, o controle psicológico e a habilidade motora adquiridos, que eu seria capaz de experimentar, a cada sessão de surfe, somente a parte prazerosa da fruição do corpo na onda e não sentiria tanto as consequências das contusóes provocadas pelos caldos, que passariam a acontecer com menos frequência.

Em uma palavra, o sofrimento estaria expurgado de minha prática e o medo estaria presente de forma moderada, conforme eu aceitasse ou não os desafios de novas ondas ou estivesse disposta a entrar em mares cada vez maiores. Para além dos hematomas, arranhões e lombalgias, existe uma disposição do surfista em lidar com cortes profundos, dentes quebrados, ruptura de ligamentos e incidentes mais sérios como tímpanos perfurados e afogamentos, se a onda valer à pena.

Às vezes dá medo, mas você aprende a lidar com isso da melhor forma. Eu quase quebrei o nariz surfando menos de meio metro no banco de areia, por exemplo, pequeno, fácil. Não é só quando tá grande, quando dá medo, que você tem que ter respeito pelo mar. Mas, eu já pensei que ia morrer duas vezes em mar grande. Várias vezes achei que seria pior do que foi. Só que mesmo com a coisa de morrer, você continua, pelo sentimento, sabe? Pelo amor ao surfe, pelo sentimento quase inexplicável de que falei. É difícil, mas não é sofrer. Hoje me divirto, mesmo quando tomo na cabeça. Você mesma, sabe que rala, entra água no nariz, mas continua surfando todos esses meses... Surfe é dedicação, não tem jeito, por isso que o surfista fala muito de amor, porque se você não tem amor ao surfe, você desiste... cansa muito no início, já reclamei, faz parte. Mas, esse amor faz você continuar porque de cara você já acha o surfe atraente, afinal é plasticamente bonito e quando você surfa... na primeira onda... ah! Quase sempre é amor a primeira vista, é mais ou menos assim que me sinto, eu acho (D.R.).
SouzA (2003) também identifica esta dimensão do esforço, mesmo entre surfistas não profissionais, de Florianópolis e o caracteriza como: "o afinco com que todos dedicavam-se ao aprimoramento de suas práticas [...] tamanha era a ênfase em seus discursos na diligência com que perseguiam suas metas, sobrepujando a dor e o cansaço”(p.13).

Depois de um longo e doloroso começo, direcionando a prancha para baixo, para o lado e avante finalmente pude experimentar a sensação de deslize, instável e escorregadia, combinada a uma preocupação extrema com manter-me de pé a fim de superar a espuma revolta que quebrava atrás de mim enquanto avançava sobre a face da onda. Quando nos distanciamos da espuma, a força se perde, a velocidade cessa e caímos. E, algumas vezes se estamos no meio da série, e não na calmaria ${ }^{32}$, as ondas não param de entrar. Portanto, temos que voltar para a superfície o mais rápido possível e buscar pela prancha para nos posicionarmos deitados novamente e remar contra elas para fazer os joelhinhos e passar a rebentação. Não conseguir fazer isso é tomar na cabeça. É quando as ondas quebram em cima de nós, nos levando para o fundo despreparados, provocando cansaço e nos arrastando cada vez mais para perto da praia, ou seja, para longe do "outside". Quando a calmaria entra iniciamos, então, outra vez o esforço de passar a rebentação, para pegarmos a próxima onda, agora já exaustos, mas motivados por repetir esta sensação de segundos.

Com o tempo e a fixação do "drop" observei outro sentido de interação com a natureza desta técnica corporal. Dizem os pesquisados, que o surfista deve fazer a manobra que a onda pede, não a que ele deseja. Isto é, um dos critérios de apreciação do "free surf 33 " e de julgamento no surfe competitivo é a adequação da manobra ${ }^{34}$ à onda. A expressão do surfista é determinada pela formação espontânea de cada onda, que "nunca é igual à outra". O bom surfista deve "fazer a linha" da onda, ou seja, correr sua parede executando manobras que estejam de acordo com sua formação. Isto vai de encontro ao que Brasil e Carvalho (2009) observou em seu estudo:

Corpo e mar, quando se encontram, podem criar experiências, na dimensão da forma e na intensidade, únicas:

[...] você tem que se integrá ao mar, você tem que tê aquele momento certo de remá, de entrá na onda, de ficá de pé, de fazê as manobras, né, de explorá a onda, consegui tirá aquele nível de surfe que ce tem, ce consegui fazê ali algumas 
manobras, né que a onda permite e... então, é demais, né (F.A.S., Itamambuca, 2005).

A prática do surfista ressalta elementos como o desafio, o contato com o diferente, com o risco, advindo de um meio imprevisível, inconstante (p.230).

Se a crista cai à frente do surfista, por exemplo, ele acelera e a contorna, "passando a sessão" ou executa o "floater", sobe a parede e se apóia no "lip" que quebra para transpô-lo; se a parede de água gira em torno de si oferecendo um tubo, o surfista se encaixa, atrasa ou acelera o "drop" e busca atravessá-lo, para a manobra ser bem sucedida é preciso entrar e sair; se é preciso manterse na parede para encadear uma sequência de manobras, rasgadas e batidas em zigue-zague mantém o surfista na linha; se o surfista excede a velocidade percebendo que a onda continua e que pode ser deixado de lado, faz um "cutback" e retorna para perto de onde a espuma está sendo jogada pela força propulsora da onda, se a parede está muito aberta e rápida ele faz um aéreo, pega velocidade e salta fazendo uma parábola no ar para aterrissar novamente de pé e continuar correndo a onda.

Para esta pesquisa, não houve tempo, e talvez nem houvesse condição física e motora por parte da pesquisadora, para a experimentação efetiva, ou bem sucedida, das sensações de todas estas manobras, mas apreendi, por saber reconhecê-las, o sentido, conferido pelo praticante, de harmonia com o inusitado que o mar oferece, de relação íntima entre o homem e a natureza, do surfista com a onda, que se pretende sincrônica.

\section{"Essa surfa que nem homem": sobre gêneros e o surfe}

É preciso dizer que encontrei mulheres surfistas nas viagens, embora muito poucas ${ }^{35}$, não havia desenvolvido há época ferramentas para precisar quantas em relação ao número de homens, visto que discutir gênero tornou-se um objetivo "a posteriori" desta pesquisa.

Entretanto, muito frequentemente, quando o destino dos surfistas era uma praia sem banheiro e quiosques, um membro novo do grupo ou alguém com quem tivessem que negociar o traslado perguntava sobre como eu os acompanharia e o que eu faria enquanto estivessem na água. A resposta "Ela pega onda também" era quase sempre seguida da pergunta "De morey ne?". E depois da resposta "Não, de pranchinha", quase sempre a expressão era de admiração ou surpresa.

Entre os surfistas universitários paulistanos, o surfe de "morey" era tido como prática menor e também como prática feminina. O consenso de que o surfe de peito é menos exigente em termos de habilidade física, motora e também o que demanda menos coragem era claro entre os surfistas de pranchinha, mas obviamente os poucos "body boarders" com quem conversei não compartilhavam desta opinião. O mesmo é encontrado por SouZA (2003) em Florianópolis:

A princípio a própria denominação de "surfista" aos praticantes de todas as modalidades de surf pareciame confusa uma vez que os surfistas que praticam o surf em pé nem sempre reconhecem como surfista os praticantes de body bording (sic). No entanto, percebi que todos auto-denominam-se como surfistas, passando então a registrar as diferenças que eles estabelecem entre as práticas e entre si (p.16).

Além disso, piadas sobre a masculinidade dos surfistas de "morey" eram constantemente feitas. Quando questionados sobre o porque desta associação os surfistas gargalhavam: "Você já viu homem que é homem gostar de ficar deitado de bunda pra cima?". Воотн (2001) e minhas vivências durante este estudo demonstram que não só os "bodyboarders", mas também as mulheres surfistas são alvos de comentários e ofensivas sexistas:

Margo Oberg remembers standing around fires to warm up after sessions in the early 1960s and "all the guys would be telling dirty, chauvinistic jokes.” In 1963, a group of boys approached a young Jericho Poppler (later a key organizer of women's professional surfing) and demanded to know where she was from: "I told them, 'Oh, I just live down there and I have three brothers' and they told me, 'You're pretty good, but why don't you come back when your tits are bigger.”' (p.4).

SouzA (2003) também identifica a presença da mulher nesse espaço, que caracteriza como de sociabilidade, o surfe em Florianópolis, como rara e relata o que chama de um certo estranhamento manifestado pela incredulidade ou pelo deboche acerca da capacidade de sua performance.

De acordo com Bоотн (2001), um contribuinte para este quadro foi a mudança, nos anos 80 , na forma como a mídia de surfe representava a mulher, na medida em que a grande maioria delas era fotografada não mais em situações de surfe, mas como corpos sexualizados, ou pedaços de corpos, posando como modelos em closes que privilegiavam, quase sempre, suas partes no biquíni. Fato que, segundo as surfistas de Florianópolis entrevistadas por VIEIRA (2007), é negativo e também existe na mídia brasileira até hoje.

Neste sentido, Bоотн (2001) demonstra como os organizadores de campeonatos, ao longo dos anos, preferiram investir mais em concursos de biquíni do que no surfe feminino durante seus eventos. 
Directors frequently cancelled events, often at short notice [...] Whatever the excuse, irregular competition in Australia prevented women from planning their season in advance and from producing attractive proposals for their potential sponsors. Women typically received only a fraction of what men earned. Men competed for A $\$ 95,000$ in the 1984 Beaurepaire Open, women for A $\$ 5,000$. [...] And as far as men were concerned the problem was simple. According to James Brisick, who had recently retired from the men's professional circuit, "there's only a small number of girls surfing at a level that...will stand up as... 'good surfing' as opposed to 'good for a girl (p.8-9).

Os surfistas estudados nesta pesquisa argumentam na mesma direção. Quando o que está em jogo é o esporte de alto rendimento, como uma mulher, mesmo que surfista profissional, no seu entender, nunca será capaz de superar um homem em força e resistência, ela talvez não mereça a mesma remuneração que ele, por não propiciar aos espectadores o espetáculo desejado.

Tem preconceito com relação à performance sim, mas tem fundamento! Porque tem tanta manobra que mulher ainda não faz... De cara tu não vê nenhum aéreo, nenhum tubão com aquela baforada cavalar. Se você pegar as melhores mulheres top top top, as melhores do WCT junto com as melhores do WQS, elas não chegam nem perto dos piores homens de cada um. Sei lá, elas surfam que nem eu assim... E tem mais, quando o mar sobe fica mais complicado ainda porque tem a questão da força (D.R.).

THORPE (2006), em seu estudo que tem por objetivo contextualizar historicamente a análise sociológica do que chama de "boarding cultures", identifica três períodos pelos quais passou o surfe, o "skate" e o "snowboard" femininos. Primeiramente corroborando com Bоотн (2001), Thorpe (2006) afirma que durante o período chamado "pre-commercial youth cultures", em meio às reivindicações e o feminismo da década de 60, de uma atmosfera de contracultura da década de 70 e de uma androgenia "punk" do começo da década de 80, os "esportes com prancha” surgiam para o mundo ocidental e a mulher era bem vinda. Estas atividades eram apropriadas por movimentos de lazer das juventudes que se consideravam alternativas e que rejeitavam o esporte tradicional, muito burocratizado e racionalizado. As novas atividades teriam uma proposta livre, divertida, cooperativa e individualista e os depoimentos das praticantes pioneiras destes esportes relatam sua aceitação. Mas, ainda em consonância com BOOTH (2001), THORPE (2006, p.216) identifica uma transição para um segundo momento:

Participation did not require masculine strength or aggression, and the respective body movements, although energetic, emphasized rhythm, grace, imagination, and fluidity. In short, these activities combined a feminine-leaning aesthetic with masculine notions of adventure and danger (Midol \& Broyer, 1995, p.208). [...] Certainly, women achieved wider acceptance in snowboarding compared with many traditional sports. [...] Nonetheless, boarding cultures became increasingly male-dominated in the late 1980s and early 1990s. [...] During this period, styles of participation that clearly privileged the male body became popular, including "bigwave" surfing and "big air" competitions in skateboarding and snowboarding. It is important to note that males were more prevalent in surfing and skateboarding before snowboarding. In fact, when the surfing population grew in the 1960s, levels of aggression in the surf also increased, and many women left the water. One female surfer recalled 1964 World Champion Phillis O'Donnel having to "scream and swear like a man to get her share of the waves. When women went into the water they. . . either had to behave like a bloke or get out" (p.215-6).

Este período, chamado pela autora de "commercial youth cultures", parece coincidir com aquele da negação da surfista mulher, e da associação dos esportes com prancha a um comportamento "radical" ao invés de "alternativo". Além disso, a "radicalidade" masculina parece ter se tornado o cerne do que ThOrPe (2006) chama de "boarding industry". E a imagem sexualizada da mulher um atrativo para o consumidor homem. Em contrapartida, a autora apresenta um terceiro momento, no final dos anos 90 e começo dos 2000, em que afirma:

Second-wave feminists typically take offense to such overtly sexualized displays, arguing that, as the product of "a backlash against women," they diminish their power, trivialize their strength, and put them in their sexual place (Burstyn, 1999, p.3). However, these young women do not see themselves as exploited or manipulated; as part of a third-wave feminist generation, they are aware of their economic worth and not afraid to state their demands. For example, professional boarder Gretchen Bleiler reminds potential sponsors that she expects them to "whip out your checkbooks" 
and "show me the money" (cited in Sherowski, 2004, p.48). If, as Wolf (1993) proclaims, "financial literacy is a goal as basic to women's empowerment as reproductive literacy," then third-wave sentiments have helped some women achieve this objective (p.265). But, as Susan Hopkins (2002) explains, if feminism in the 1970s was built on ideals of authenticity and solidarity, girl power in the twenty first century rests on the dreams of celebrity and self-advancement"(p.221).

Ou seja, para a autora "female boarders" não são simples vítimas da falta de espaço e remuneração ou da comercialização de suas imagens, mas agentes ativas que formatam e reformatam as imagens e significados circulados neste mercado da juventude. Mesmo que estes constrangimentos ideológicos do segundo período das, chamadas por ela, "boarding cultures" tenham isolado e desencorajado muitas mulheres, outras lutaram contra a marginalização.

Segundo THOrPe (2006), uma segunda e terceira ondas feministas influenciaram mulheres que se prepararam para vestir-se e falar "como um dos caras" e provar seus níveis masculinos de dedicação e habilidade. Outras delas desafiaram as instituições esportivas dominadas por homens criando coletivos, agências e campeonatos exclusivamente femininos via camaradagem e filosofias "do-your-self". E outras ainda utilizaram-se de seu "sex appeal" para estar no esporte, encontraram espaço promovendo sua heterosexualidade feminina e o que a autora chama de "female boarding body". Enfim, todas elas contribuíram para que o número de mulheres praticantes de "esportes com prancha" aumentasse neste período e a "female boarding culture" se tornasse, ela mesma, um forte nicho de mercado.

As well as a new set of girl power ideologies, and the increasingly visible role of the female athlete in the broader society, several other factors contributed to the escalating number of female boarders in the late 1990s and 2000s. The inclusion of females in globally televised events, including the X-Games and Olympics, and blockbuster movies focusing on female surfers such as Blue Crush (2002), added to the visibility and legitimization of the female boarder. As a result, the number of female boarders exploded (Thorpe, 2006, p.219).

Mas, embora na presente pesquisa tenha-se encontrado mulheres que podem ser caracterizadas como exercendo o "girl power", confortáveis com a exposição de seus corpos, satisfeitas com acessórios e equipamentos específicos para mulheres e transitando livremente entre estilos suaves ou agressivos de surfe, em São Paulo, elas eram ainda muito poucas e suas reivindicaçōes corroboram com aquelas apresentadas por Bоотн (2001) segundo o qual a performance feminina em geral é associada "a priori” à inferioridade técnica.

Entre os surfistas estudados, uma surfista de pranchinha, como eu, ainda era vista como uma destemida em ambiente masculino e, embora, na maioria das vezes, incentivada, era também rabeada ${ }^{28}$. E quando uma surfista de pranchinha apresentava performance ótima o elogio que se ouvia em muitas circunstâncias era: "Essa surfa que nem homem, essa é casca grossa!".

Isto pode estar de acordo com o que BоOTH (2001) preconiza em seu estudo. Embora pareça haver certa aceitação, o número ainda diminuto de surfistas mulheres, em comparação ao de surfistas homens, sugere que aquelas poucas que persistem correspondem às exceções de uma regra de resistência masculina:

When you first paddle out," Appleby says, "all of the guys will be waiting to see what you do on your wave. Once you get a good one, they're like, 'OK, she's all right.' [...] But, as this article has demonstrated, much of this evidence is superficial. There are no more than two dozen genuine big-wave riders and they mostly lead isolated and solitary lives. Even Lisa, the correspondent to Chick magazine above, concedes that she is "usually the only girl [in the water] (p.16).

Воотн (2001), em seu estudo diacrônico, demonstra como as atletas que não praticavam o "girl power”, rejeitando as limitaçôes de um estereótipo feminino para seu surfe, e que atingiam o estágio avançado de radicalidade e aparência atlética, passavam a ser vistas como desviantes e especulações sobre sua sexualidade passavam a acontecer.

Em um estudo sincrônico, Moura, Santos, BENTO e LovisOlo (2010) afirmam que a habilidade esportiva e persistência também foram encontradas como passaportes para a aceitação das mulheres no espaço do futebol e do MMA. Mas, convergindo com Воотн (2001), a permanência das praticantes nas modalidades foi identificada como algo que ainda desperta desconfiança sobre sua orientação sexual.

Isto vai de encontro ao que aponta HuMBERSTONE (2007): mesmo que os esportes na natureza, a educação ao ar livre ou pela aventura tenham o potencial de promover novas condutas e sensibilidades políticas com relação à natureza, o esporte pode continuar a ser território da hegemonia masculina. E a natureza pode ser usada para reforçar a dominância de gênero.

A natureza não representa somente as colinas ondulantes e paisagens pitorescas da Inglaterra, mas, 
também, um 'lugar selvagem', onde os homens têm testado sua masculinidade contra os perigos dos elementos naturais por meio da exploração e da aventura no mar e nas montanhas. A reportagem da morte de Alison Hargreaves, enquanto descia a difícil montanha K2, no Himalaia, em 1995, destaca as formas como a 'natureza' selvagem é designada: um espaço masculino e inapropriado para mulheres. Hargreaves, considerada uma das melhores montanhistas da Grä-Bretanha, tinha experiência e era habilidosa e competente. Ela havia subido, com sucesso, vários picos do Himalaia naquele ano. No mesmo mês de sua morte, dois homens também morreram ao descerem uma montanha no Himalaia. Esses montanhistas foram relatados como 'homens de grande integridade e tremenda estatura', enquanto Hargreaves foi proclamada uma mãe inapta e 'obcecada' pelo desejo de chegar ao topo. Não foi mencionado que um dos homens era também pai. Essa reação, quase violenta, à transgressão da montanhista habilidosa reforça a montanha como território masculino, como "lugar selvagem', onde as mulheres estão fora de lugar e aonde não deveriam ir (HuMBERTONE, 2007, p.29).

Nesta pesquisa, no "outside", o que chamou atenção é que tanto as mulheres quanto os "body boarders" eram muitas vezes rabeados. E mesmo que isto não acontecesse, quando o "body boarder" ou a surfista de pranchinha tinha a prioridade da onda reclamações do tipo "Não acredito que perdi aquela direitona pra um viado/pra uma cocota!" eram ouvidas.

Embora a regra de prioridade pela onda pareça endereçar a segurança e conferir ao surfista, independentemente do nível de proficiência ou talento, o direito de pegar as ondas nas quais se posiciona, quando questionava porque alguém havia me $\mathrm{ra}$ beado as respostas eram "Pensei que você não fosse conseguir entrar na onda.", "Achei que você tivesse desistido porque estava grande" ou "A onda estava muito boa, você não ia saber aproveitar”. É importante ressaltar que as justificativas para as rabeadas e reclamações na maioria das vezes estavam relacionadas à inferioridade técnica atribuída às mulheres e aos "body boarders". Caso se disputasse uma onda com uma surfista ou "bodyboarder" profissional ou que estivesse se sobressaindo em termos de performance, raramente reclamaçôes e rabeadas eram observadas.

Dominação e preconceito aparecem no surfe, então, como entre os gêneros praticante e não praticante ou bom surfista e mal surfista, o do surfe e o haoli, aquele que quebra ${ }^{39}$ e aquele que é prego ${ }^{40}$, e não entre homem e mulher necessariamente. Entretanto, como o referencial comparativo é sempre o masculino, pode-se dizer, a partir do campo deste estudo, que a masculinidade surfista é marcante nas dinâmicas do grupo acompanhado.

\section{Considerações finais}

No âmbito metodológico, e como objetivo segundo deste estudo, levar ao limite a prerrogativa antropológica segundo a qual se constrói o conhecimento sobre aquele que é estudado a partir do seu ponto de vista, não só por levar a sério o que os surfistas dizem sobre o que fazem e sobre si mesmos, mas por buscar construir um corpo surfista, a partir do qual olhar, reforçou a importância do corpo do pesquisador na investigação sobre culturas cinéticas.

Sobre o objetivo primeiro desta pesquisa, vivendo e descrevendo as dinâmicas do surfe encontrei os significados da relação do surfista com o mar nas sensações corporais experimentadas nas técnicas do remar, sentar, dar o joelhinho e dropar a onda. Que ser capaz de passar a rebentação é associado a um retorno bem sucedido e/ou permitido à comunhão do homem com a natureza, sendo as cores, formas e sensaçôes do "outside" o prêmio para aquele que vence as dificuldades do tornar-se e ser surfista.

Entretanto, estas sensações são tidas como possibilidades de corpos corajosos e ágeis, "a priori”, entendidos como corpos masculinos. O surfe como campo em que o feminino é visto ainda como exceção dá a pensar que os esportes na natureza, a educação ao ar livre ou o turismo de aventura, embora tenham potencial de promover novas condutas políticas e a virtuosa sensibilidade ambiental, não estão livres de reproduzir outros padrōes de dominação. 


\section{Abstract}

"From the outside": body and nature, fear and gender in surfing

The main goal of this research is to describe the dynamics of surfing and its meanings, mainly the human/ nature relation established through the sport. Meanwhile, other goals were added: discussing the approach to the field by the researcher, the possibility this researcher could investigate through her own body and the gender matter in the sport. About the main aim of the research, living and experiencing the sport itself, meaning, to the relation between the surfer and the sea, was found in the body sensations experienced through techniques such as paddling, sitting, duck diving and dropping a wave. Being able to go out is associated to a successful return to man's communion with nature, making outside's colors, shapes and sensations the privilege of whoever transposes the challenges and difficulties of becoming and being a surfer. However, these sensations are held as being only possible for courageous and agile bodies, at first, understood as male ones. Surfing as a field where the feminine is still the exception, allows the thinking that, even though nature sports and outdoor education have the potential to promote new political conducts and environmental sensitivity virtues, they are not free from reproducing other domination standards.

UnITERMS: Surfing; Nature; Body; Risk; Gender.

\section{Notas}

1. O desdobramento de pesquisa que apresento neste artigo é uma releitura dos dados à luz de discussóes com Carlos Eduardo Costa, Daniel Ramos da Fonseca, Daniela Nagy, Gil Vicente Lourenção, Messias Basques e Thaís Mantovanelli, novos interlocutores, colaboradores e colegas de Antropologia a quem devo meus agradecimentos.

2. Termos grafados em itálico correspondem neste texto a expressões próprias ao campo etnográfico ou palavras estrangeiras. Incluídos os termos cultura e natureza, ideias mediadas sociologicamente. Embora alerta ao interesse da antropologia por discussões sobre a oposição natureza/cultura e do perigo da "essencialização" desses termos, os tomo neste texto, uma primeira aproximação com o campo, tal qual os agentes da pesquisa os entendem e não enquanto conceitos teóricos.

3. O surfista detém amplo conhecimento do que classificamos como geologia, geografia, meteorologia, oceanografia, biologia marinha, engenharia naval, entre outros campos. É surpreendente notar como estes saberes são operados e determinam o sucesso do "empreendimento surfístico" tanto em termos de satisfação com a sessão de surfe, como de segurança. O mesmo foi notado por SouZA (2003): "Perguntava também como liam o mar, sendo este um item ao qual me dediquei, o que exigiu grande esforço e mostrando-se um ótimo ponto para começar conversas interessantes. Tentei aprender a reconhecer as formações do mar "in loco", que correspondem às classificações que empregam, na medida em que também tentava aprender sobre correntes marinhas e direçôes dos ventos, não obtendo aí tanto sucesso mas chegando a apreciar a especificidade do conhecimento que o surfista dialoga em seu cotidiano" (p.18).

4. CEP/0202006/EEFE/03032006, protocolo de pesquisa n.69.

5. Termo nativo para "viagens de surfe".

6. Bertioga é localizada à $120 \mathrm{~km}$ de São Paulo, São Sebastião à $203 \mathrm{~km}$. Quando se desce a Serra do Mar pelo complexo Anchieta-Imigrantes, deve-se entrar na Rodovia Prestes Maia (SP-055/BR-101 Rio-Santos), sentido Rio de Janeiro. Bertioga é o primeiro município e pode-se ver da estrada a extensa praia da Boracéia (acesso pelo km 190), que faz divisa com o município de São Sebastião no qual se encontra as praias, pela ordem: Juquehy (acesso km 176), Praia da Baleia (acesso km 172), Camburi (acesso km 165), Maresias (acesso km 163), Paúba (acesso151 km).

7. Guarujá é localizado à 87 km de São Paulo. Após o complexo Anchieta-Imigrantes continua-se na rodovia PiaçagueraGuarujá (hoje Rodovia D. Domênico Rangoni). O Guarujá está localizado à 30 km de Bertioga.

8. Os filmes de surfe são muito importantes no universo dos surfistas e esta temática será explorada em outro artigo. Sendo, por eles, considerados um gênero cinematográfico específico, todos os surfistas paulistanos estudados possuíam arquivos pessoais e assistiam com frequência filmes considerados clássicos e procuravam se manter atualizados assistindo novos filmes, sempre lançados. SouZA (2003) também deparou-se com esta formulação em Florianópolis: "compreendi também a importância que os surfistas atribuem aos próprios filmes e ao filmar-se, se a princípio as imagens pareciam-me sempre 
as mesmas, ou seja, homens surfando em ondas azuis, aos poucos fui aprendendo a diferenciar e apreciar as manobras que faziam em diferentes formações marítimas espalhadas pelo mundo, imagens estas que os surfistas procuram imitar a medida que consideram a manobra bem executada. Os filmes são para eles fonte de deleite e aprendizagem, de tal modo que "filmes de surf" constituem-se hoje em um gênero cinematográfico cuja projeção, em Florianópolis, não fica restrita a pequenas salas ou horários vespertinos, ocorrendo, durante os meses de verão, nos principais cinemas da cidade em horários nobres" (p.20). Em especial para o presente estudo note-se que filmes de surfe feminino são mais raros. E mulheres surfistas aparecem muito pouco em filmes de surfe em geral, que normalmente se dedicam aos surfistas homens. 9. Sinônimo de surfar ou referente a conseguir entrar em uma onda, quando em situação de prática.

10. A rebentação é a porção do mar onde quebram as ondas. Para surfar uma onda satisfatoriamente é preciso pegá-la antes da rebentação ("outside"), por isso a necessidade de passá-la. Também chamado "varar a rebentação" ou "chegar ao outside".

11. Porção do mar que se localiza, da areia para o fundo, após a rebentação. Em oposição ao inside que seria o local mais raso, antes da rebentação.

12. Souza (2003) também relata dificuldade em interagir com surfistas quando se está procurando estabelecer relações na areia: "Enquanto muitos colegas, antropólogos ou não, dirigiam a mim ironias pela aparente facilidade de uma pesquisa na praia, eu, na praia, ficava olhando o relógio nervosamente depois da primeira hora e meia de observação no local” (p.12).

13. Com o intuito de reparar quaisquer equívocos da impressão da pesquisadora, antes da publicação, este texto foi oferecido aos estudados para correção.

14. Quando se cai da onda não propositalmente e se é segurado no fundo e arrastado para o raso pela força da água.

15. Localismo é o termo nativo para os conflitos que se estabelecem quando surfistas locais, ou seja, nascidos ou que moram na praia em questão restringem seu uso por surfistas não locais, delimitando o espaço de piores ondas para eles, ou impedindo-os de entrar no mar ou na praia de maneira violenta.

16. "Lip" ou crista é a porção da onda que primeiro quebra. É a parede da onda quando ela gira em torno de si. Porção de água arremessada para a frente, eventualmente por cima do surfista, formando um tubo.

17. A remada se caracteriza pela posição deitada na prancha, em decúbito ventral e o movimento alternado dos braços, com a mão em concha e mantendo a extensão de coluna.

18. A espuma é a substância branca ou escura produzida quando a onda quebra e que depois se desfaz.

19. As marolas são ondulações pequenas e suaves, que não quebram, apenas balançam o surfista passando por baixo dele.

20. Suportar permanecer sem respirar.

21. O joelhinho é a técnica de furar a onda, ou seja, afundar a prancha e mergulhar com ela para atravessá-la, ou passar por debaixo dela enquanto quebra, evitando ser atingido ou arrastado.

22. Também chamado pézinho ou golfinho.

23. Porção traseira da prancha. Onde está preso o "leash", também chamado estrepe ou cordinha.

24. O vento precisa ser percebido pelo surfista e avaliado porque ele interfere na formação das ondas. Além de sua direção (leste, oeste, norte, sul, sudeste, sudoeste, noroeste e nordeste) o mais básico que se precisa saber sobre ele é se é terral, sopra da terra para o mar, e por isso favorece a formação das ondas como se as penteasse e sua força sustentasse por mais tempo a parede da onda em pé, ou seja, surfável; e o maral que sopra do mar para a terra e empurra a parede da onda por trás de forma que ela fecha mais rapidamente, prejudicando o surfe.

25. Estas novas formas são representadas em desenhos muito peculiares feitos pelos surfistas e levam aqueles que se dedicam à arte a fazer, muitas vezes, do surfe seu tema e sua inspiração no processo de criação. Há museus como "Legends" (em Maresias) e eventos (como o Festival de Arte e Cultura Surf, que agora chama-se Festiv'alma) que compilam destas variadas obras (esculturas, telas, instalaçōes, fotografias, vídeos) as consideradas admiráveis por esta estética específica e compartilhada entre os surfistas.

26. É possível comparar a sensação de um iniciante aprendendo a sentar àquela do desafio de permanecer em um "touro mecânico".

27. As ondas chegam à costa em séries, conjuntos de duas à cinco ondas aproximadamente, que entram na praia sem intervalo, seguidos de um período sem ondas que é chamado calmaria. Conjuntos de séries são chamados ondulação ou "swell".

28. Porção do "lip" da onda que é primeiro propulsionada. Nos casos ideais, a parede da onda se forma como um triângulo, o pico seria seu ápice. Note-se que pico também pode significar praia ou porção de praia onde quebram boas ondas.

29. Quando, por acidente, o bico da prancha submerge e faz com que o surfista seja projetado para a frente dela num golpe brusco que é seguido de um caldo no qual se corre o risco de ser atingido pela prancha que é jogada circularmente junto com o surfista pelo turbilhão de água.

30. Sinônimo de caldo. Tombo da prancha.

31. Vaca, tombo específico, quando a onda fecha em cima do surfista. 
32. A calmaria é o período de tempo, entre as séries, no qual não entram ondas. É o período ideal para se tentar passar a rebentação. Dependendo da frequência e tempo das séries, é possível passar pelo local da rebentação durante a calmaria sem precisar dar sequer um joelhinho e chegar ao "outside” praticamente secos. E há dias em que praticamente não há calmaria e as ondas quebram, como dizem os surfistas "uma atrás da outra” ou "não param de entrar". Quanto maiores as ondas, mais difícil o joelhinho, por que ele precisa ser mais fundo, e, quando mal dado, maior o arrasto que nos leva em direção a praia e mais longe de nosso objetivo que é chegar ao "outside", portanto, mais importante a calmaria. Depois que entendi e aprendi a ver e usar a calmaria ela me remeteu à frase de Zé Ramalho na música Ondas Eternas: "Quanto tempo temos antes de voltarem aquelas ondas".

33. "Free surf” é o surfe não competitivo. Há surfistas profissionais que são competidores, e os que são "free surfers", ou seja, que não participam de campeonatos, mas que pela sua qualidade técnica recebem patrocínio, normalmente em troca dos direitos de suas imagens.

34. Manobrar é não só correr a onda, mas fazê-lo explorando-a, desafiando-se, exibindo destreza e controle. Algumas formas de fazê-lo tornaram-se consensuais, foram batizadas e são reconhecidas como respostas possíveis a certas formaçōes de onda.

35. O mesmo foi notado por Souza (2003, p.10): e está relatado em sua introdução: "Quando minha irmã começou a surfar passei inúmeras horas, no papel de irmã mais velha, ouvindo seus relatos sobre o esforço e o tempo despendidos naquilo que me parecia tão simples: ficar em pé numa tábua. Eram divertidas as histórias sobre o que rolava no tempo de espera, o espaço do mar onde se aguarda boas ondas e onde os adeptos do esporte se conhecem e se encontram, numa proporção hipotética de talvez duas ou três mulheres para cada trinta homens. O tempo passou, o sol escasseou, o mar se tornou cinza e bravio, o frio, a chuva e o inverno se instalaram mas sua determinação em conseguir equilibrar-se em movimento sobre um meio aquoso não arrefeceu”.

36. "Morey Boogie" ou "Body Board", surfe de peito que utiliza-se de prancha pequena, aproximadamente do tamanho do tronco do surfista e pés de pato para propulsão. Ao invés de remar, se entra na onda batendo pernas. Segundo KAMPION e BROWN (2003) esta prancha foi criada por Tom Morey em 1971 e popularizou-se como brinquedo aquático para crianças, sendo mais barata e fácil de transportar foi adquirida pelo público em geral e levada para piscinas, lagos, etc.

37. WCT: World Championship Tour; WQS: World Qualifying Series (divisão de acesso ao WCT). Ambos são circuitos competitivos organizados pela Association of Surfing Professionals. Hoje, o WCT tornou-se WT (World Tour).

38. A ação de dropar uma onda impossibilitando outro surfista melhor posicionado de correr a parede desta onda, é chamada rabear. As rabeadas acontecem por acidente ou quando um praticante entende ter mais autoridade ou habilidade no surfe que outro.

39. Quebrar ou quebrar a onda significa surfar muito bem, dispor de muitas manobras em alto gau de dificuldade e radicalidade.

40. Sinônimo de haoli, aquele que não surfa ou que surfa mal.

\section{Referências}

BOOTH, D. From bikinis to boardshorts: wahines and the paradoxes of surfing culture. Journal of Sports History, Los Angeles, v.28, n.1, 2001.

BOURDIEU, P. Programa para uma sociologia do esporte. In: Coisas ditas. São Paulo: Brasiliense, 1990.

BRASIL, F.K.; CARVALHO, Y.C. Pescadores artesanais, surfistas e a natureza: reflexões a partir de um olhar da educação física. Movimento, Porto Alegre, v.15, n.1, p.217-39, 2009.

DAÓLIO, J. A antropologia social e a educação física: possibilidades de encontro. In: CARVALHO, Y.M.; RÚBIO . K. (Orgs.). Educação física e ciências humanas. São Paulo: Hucitec, 2001. p.105-14.

HUMBERSTONE, B. 'Transgressōes de gênero e naturezas contestadas'. Revista Brasileira de Ciências do Esporte, Campinas, v.28, n.3, p.21-38, 2007.

KAMPION, D.; BROWN, B. Stoked: uma história da cultura do surf. Lisboa: Taschen, 2003.

MAUSS, M. Técnicas corporais. In: Sociologia e antropologia. São Paulo: Cosac Naify, 2003.

MIDOL, N. Cultural dissents and technical innovations in the 'whiz' sports. International Review for the Sociology of Sport, London, v.28, n.1, p.23-32, 1993.

MIDOL, N.; BROYER, G. Towards an anthropological analysis of new sport cultures: the case of whiz sports in France. Sociology of Sport Journal, Champaign, v.12, p.204-12, 1995.

MOURA, D.; SANTOS, F.; BENTO, G.; LOVISOLO, H. Esporte, mulheres e masculinidades. Esporte e Sociedade: Revista Digital, Niterói, v.5, n.13, 2009/2010. Disponível em: <http://www.uff.br/esportesociedade/pdf/es1304.pdf>. 
SOUZA, A. M. “Evoluindo”: mulheres surfistas na Praia Mole e Barra da Lagoa. 2003. Dissertação (Programa de PósGraduação em Antropologia Social) -Universidade Federal de Santa Catarina, Florianópolis, 2003.

THORPE, H. 'Beyond decorative sociology: contextualizing female surf, skate and snow boarding'. Sociology of Sport Journal, Champaign, v.23, n.3, p.205-28, 2006.

VASCONCELOS, E.; RAMOS, V.; STEINMEIN, J.; BOTELHO, L.; NAHAS, M. Características demográficas e estilo de vida de surfistas brasileiros. In: CONGRESSO BRASILEIRO DE ATIVIDADE FÍSICA \& SAÚDE, 1., Florianópolis, 1997. Anais... Florianópolis: UFSC, 1997. p.98.

VIEIRA, R.M.B. Cultura surf em Florianópolis: a voz das surfistas. In: ENCONTRO REGIONAL SUL DE HISTÓRIA ORAL, 4., 2007. Caderno de Resumos... Florianópolis: UFSC, 2007. Disponível em: <http://www.cfh.ufsc.br/abho4sul/ pdf/Roberto\%20Milton\%20Brasil\%20Vieira.pdf>.

SPRADLEY, J. Participant observation. San Francisco: Holt, Rinehart and Winston, 1980.

WACQUANT, L. Corpo e alma: notas etnográficas de um aprendiz de boxe. Rio de Janeiro: Relume Cumará, 2002. WHEATON, B. "Just do it": consumption, commitment, and identity in the windsurfing subculture. Sociology of Sport Journal, Champaign, v.17, p.254-74, 2000.

Recebido para publicação: 16/ 06/ 2008

Marília Martins Bandeira 1a. Revisão: 13/10/2008

2a. Revisão: 30/05/2009

Al. J undiaí, 235 - Residencial 4 - Alphaville 06542-085 - Santana de Parnaíba - SP - BRASIL e-mail: martins.marilia@yahoo.com.br

3a. Revisão: 02/ 10/2010

4a. Revisão: 02/09/2010

5a. Revisão: 24/ 09/2010

Aceito: 05/ 10/2010 